\title{
WHO save lives: Clean your hands *
}

\author{
Newsletter
}

\section{September 2009}

\section{Dear Colleagues,}

Last month, WHO Patient Safety hosted a two day technical meeting in Geneva for representatives from countries where hand hygiene campaigns are already operating. The newsletter this month gives you a snapshot of the meeting and some of the discussions that took place. But first, Save Lives: Clean Your Hands is gearing up to raise the registrations ahead of May 2010.

\section{0,000 for 2010}

It's our new catchcry. By 5 May this year, we had tipped the 5000 mark for hospitals and facilities worldwide to celebrate improvements in hand hygiene. By 5 May next year, we are aiming for 10,000 registrations. To do this we will need your help. Word of mouth is one of the best ways, as are contacting colleagues, talking to other health professionals and using your networks. We will swing into action with a revitalized campaign very shortly - all details and information will be available on the website.

\section{Campaigning countries get together}

In August more than 50 participants from a wide range of countries came together in Geneva for a two-day technical meeting. The majority of the attendees represented countries where hand hygiene campaigns are now operating or about to begin, and were energized by some spirited debate and discussion on the approaches different campaigns have adopted. It is very encouraging to see the extent to which hand hygiene is being used as a critical means of reducing health care-associated infection (HCAI) and is motivation for us all in continuing with our activities to improve and sustain hand hygiene in all our work places.

Professor Didier Pittet as the expert lead for the First Global Patient Safety Challenge: Clean Care is Safer Care stressed the ongoing importance of hand hygiene and the contribution WHO Patient Safety has made since the programme was initiated four years ago. His presentation was followed by a session on "patient voices" which covered some of the consequences that HCAI bring to patients and their

\footnotetext{
* Reprinted by permission from the WHO 'Save Lives: Clean Your Hands' monthly newsletter, Update No. 12, 8 September 2009, seen at http://www.who.int/gpsc/5may/news/update12/en/index.html, @ World Health Organization 2009.
} 
families. Another session included the results of an international survey on the current status of the various hand hygiene initiatives in different countries. A report on this work will be posted on the website shortly.

Many participants contributed to the event with oral and poster presentations prompting discussion and interaction. One of the key recommendations was that facilities should adopt a more multidisciplinary approach to hand hygiene improvement at local level, which can be highly rewarding but challenging to achieve.

One of the major items on the agenda was how to progress the concept of a network of countries where campaigns are already in place or about to begin. The capacity to share knowledge, experiences, issues and concerns is an important aspect of the network. A full report on the Geneva meeting will be available from the website as well as ongoing information on the activities of campaigning countries.

\section{Case studies for shared learning}

A warm thank you to many of you who are sending us hand hygiene case studies reflecting the work being achieved in their local areas. As always, putting these case studies on the website poses some challenges and we are currently putting together some additional guidelines as well as information about the process here at WHO for uploading them.

Hand Hygiene Implementation Tools - as you will be aware a number of implementation tools are available at http://www.who.int/gpsc/5may/tools/en/index.html. At this time, some updated tools have been placed on these pages, in an attempt to make the tools as clear and user-friendly as possible. Information will be available on the changes that have been made to existing tools to make it easy for you to understand. We always encourage you to check our web pages regularly for any updates, especially to the tools that you might be using in your areas. We have also introduced a new "opening" page to the tools, following requests to highlight some key tools in the first instance, however we should emphasise that in order to implement a successful multi-modal hand hygiene improvement strategy the full range of tools available are all important.

All information about the Challenge team and contact inquiries are available at: http://www.who.int/ gpsc/en/ and http://www.who.int/gpsc/background/en/index.html.

Specific enquiries can be sent to savelives@who.int.

Thank you all for your ongoing support and enthusiasm.

Claire Kilpatrick

Programme Manager

First Global Patient Safety Challenge: Clean Care is Safer Care 